\author{
Contato \\ Departamento de História - IFCH - Unicamp \\ Rua Cora Coralina, 100 \\ 13083-896 - Campinas - SP \\ shlara@unicamp.br
}

\section{DEPOIS DA BATALHA DE PUNGO ANDONGO (1671): O DESTINO ATLÂNTICO DOS PRÍNCIPES DO NDONGO*}

\author{
Silvia Hunold Lara**
}

Universidade Estadual de Campinas

Campinas - São Paulo - Brasil

\title{
Resumo
}

Em dezembro de 1671, depois de um cerco de vários meses, as tropas comandadas por Luís Lopes de Sequeira conseguiram tomar a capital do Reino do Ndongo. O rei foi morto e houve muitos prisioneiros, entre eles parentes do soberano, que foram deportados para o Brasil e depois para Portugal. O artigo procura reconstituir o périplo dos príncipes do Ndongo no exílio, discutindo seus significados tendo em vista o contexto do avanço colonial pelos sertões de Angola, os dilemas das autoridades na América portuguesa e as políticas metropolitanas em relação aos africanos em Portugal. Cruzando processos que se desenvolveram em Angola, no Brasil e em Portugal, procura-se compreender os motivos pelos quais os herdeiros do Reino do Ndongo não foram escravizados, como a maioria dos prisioneiros feitos naquela batalha.

\section{Palavras-chave}

Reino do Ndongo - tráfico de escravos - africanos em Portugal.

* Este artigo foi apresentado no workshop "Towards the Angolan past", promovido pelo Harriet Tubman Institut, York University, Toronto (Canadá), em 6 de maio de 2013. Uma versão em inglês do texto integra a coletânea organizada por BURI, Maryann \& CURTO, José C. (ed.). New perspectives on Angola: From slaving colony to nation state. Kentucky: The University Press of Kentucky. A pesquisa está vinculada a um projeto mais amplo financiado pelo Conselho Nacional de Desenvolvimento Científico e Tecnológico (CNPq) e pela Fundação de Amparo à Pesquisa do Estado de São Paulo (Fapesp). Agradeço a Laura Peraza Mendes pela localização de alguns dos documentos e a Alexandra O. Alberini pela ajuda em decifrar algumas das informações geográficas aqui mencionadas. Agradeço também aos pareceristas ad hoc da Revista de História pelos comentários e sugestões.

** Bacharel em História e doutora em História Social pela Universidade de São Paulo. Professora titular e colaboradora do Departamento de História do Instituto de Filosofia e Ciências Humanas da Universidade Estadual de Campinas (Unicamp). 
rev. hist. (São Paulo), n. 175, p. 205-225, jul.dez., 2016 http://dx.doi.org/10.11606/issn.2316-9141.rh.2016.121827
Silvia Hunold Lara

Depois da Batalha de Pungo Andongo (1671): 0 destino atlântico dos príncipes do Ndongo

\section{THE AFTERMATH}

OF THE BATTLE OF

PUNGO ANDONGO

(1671): THE ATLANTIC

FATE OF THE PRINCES

OF NDONGO

Silvia Hunold Lara

Universidade Estadual de Campinas

Campinas - São Paulo - Brasil

\section{Abstract}

In December 1671, following months of siege, the troops led by Luís Lopes de Sequeira were able to overtake the capital of the Kingdom of Ndongo. In the process, the king was killed and many prisoners were made. Included amongst the latter were relatives of the sovereign who were deported to Brazil and Portugal. This paper seeks to reconstruct the journey of the princes of Ndongo in exile, analyzing their significance within the context of colonial penetration of the interior of Angola, dilemmas facing authorities in Portuguese America, and metropolitan policies relating to Africans in Portugal. Crossing processes that took place in Angola, Brazil and Portugal, the overarching objective of this paper is to understand the motives through which the inheritors of the Kingdom of Ndongo did not become slaves, as was the case with most of the prisoners taken in that battle.

\section{Keywords}

Kingdom of Ndongo - slave trade - Africans in Portugal. 
rev. hist. (São Paulo), n. 175, p. 205-225, jul.dez., 2016 http://dx.doi.org/10.11606/issn.2316-9141.rh.2016.121827
Silvia Hunold Lara

Depois da Batalha de Pungo Andongo (1671): 0 destino atlântico dos príncipes do Ndongo

Em 1671, ao avançar para o interior da África central, os portugueses tiveram que enfrentar mais uma vez o rei do Ndongo, que resistia ao domínio português havia algum tempo, dificultava as comunicações com os jagas de Kasanje e atrapalhava as rotas comerciais que levavam ao Cuango. Dom João Ari (Ngola Hari) havia atacado algumas caravanas e se retirado para a capital, na região de Pungo Andongo (Pungu-a-Ndongo ou Pedras de Mupungo). Em agosto, sob o comando de Luís Lopes de Sequeira, formou-se uma grande tropa, que incluía soldados brancos e negros de Muxima, Massangano e Cambambe, da Ilamba e do Lumbo, e reforços enviados do Brasil. A campanha foi difícil e, depois de um cerco de vários meses, em 29 de novembro daquele ano, os portugueses conseguiram tomar a capital. Vitoriosos, estabeleceram um forte no local que, ao mesmo tempo, marcava o avanço do domínio português no sertão centro-africano e o fim do Reino do Ndongo.

Uma descrição detalhada dos eventos foi feita por Antônio de Oliveira Cadornega, que declina nomes de soldados e comandantes e destaca a importância política e comercial da vitória sobre o Ndongo. ${ }^{1} \mathrm{O}$ feito militar teve certa repercussão em Portugal, como mostra um relato publicado em Lisboa, atribuído ao conde da Ericeira, um dos integrantes mais proeminentes da corte portuguesa no período. Escrita para enaltecer o então governador de Angola, Francisco de Távora, o relato descreve as batalhas e o cerco a Pungo Andongo, nomeando os principais soldados que participaram dessa guerra - tudo para fundamentar o pedido de prorrogação do mandato do governador por mais três anos. ${ }^{2}$ Apesar de os dois textos mencionarem terem sido muitos os "inimigos" mortos, não há detalhes sobre os prisioneiros feitos ao longo de tantos meses de luta.

${ }^{1}$ CADORNEGA, Antônio de Oliveira. História geral das guerras angolanas, tomo II. Anotado e corrigido por José Matias Delgado. Lisboa: Agencia Geral do Ultramar, 1972 [1680], p. 298-329.

2 Cf. [MENEZES, dom Luís de (3. ${ }^{\circ}$ conde da Ericeira)]. Relação do felice successo que conseguiram as armas do serenissimo principe dom Pedro, nosso senhor, governadas por Francisco de Tavora, governador e capitão general do Reino de Angola, contra a rebellião de dom João, rei das Pedras e Dongo, no mez de dezembro de 1671. Lisboa: Miguel Menescal, s.d. BNL, RES 903P, n. 11. Publicado por BRÁSIO, Antônio (ed.). Monumenta missionaria africana, vol. X. Lisboa: Agência Geral do Ultramar, Divisão de Publicações e Biblioteca, 1952-1988 (doravante MMA), doc. 64, p. 143-152. A atribuição de autoria é feita por MACHADO, Diogo Barbosa. Bibliotheca Lusitana, vol. 3. Lisboa ocidental: António Isidoro da Fonseca, 1752, p. 118. É provável que tenha sido publicada em 1673, pelo que se depreende de um manuscrito reproduzido por FELNER, Alfredo. Angola. Coimbra: Imprensa da Universidade, 1933, doc. 43, fotogravura entre as p. 468-469 e publicado sob o título Batismo do príncipe de Dongo, em MMA, vol. XIII, doc. 125, p. 297-298. A. Brásio data este manuscrito de $1^{\circ}$ de maio de 1674. 
rev. hist. (São Paulo), n. 175, p. 205-225, jul.dez., 2016 http://dx.doi.org/10.11606/issn.2316-9141.rh.2016.121827
Silvia Hunold Lara

Depois da Batalha de Pungo Andongo (1671): 0 destino atlântico dos príncipes do Ndongo

O relato atribuído ao conde da Ericeira indica que, na batalha final, "foi grande o número de prisioneiros", mas observa que tiveram pouca valia, "porque a maior parte deles eram de certas gerações que por lei estabelecida são isentas do cativeiro". ${ }^{3}$ Segundo Cadornega, também foram muitos os capturados logo depois de as tropas entrarem em Pungo Andongo, quando os soldados brancos e pretos saquearam "tudo o que acharam". Foi "esbulho de consideração", diz ele, já que o rei e seus aliados, achando-se seguros no interior daquele sítio cercado pela barreira de pedras, haviam levado consigo muitos de seus súditos e "tudo o que possuíam". ${ }^{4}$ A documentação administrativa indica que o quinto real chegou a $710 \$ 200$ réis e deve ter sido grande o contingente de presos enviados para o tráfico atlântico. ${ }^{5}$

Cadornega relata ainda que o rei dom João Ari refugiou-se no Libolo, ao sul do rio Cuanza, mas, ao ser entregue aos portugueses, recusou-se a seguir viagem e foi decapitado para evitar que pudesse ser resgatado por seus aliados. ${ }^{6}$ Seu filho, dom Felipe, e dom Diogo Cabanga, irmão do rei e comandante de seus exércitos, esconderam-se em Matamba, a leste do rio Cuango, mas também foram devolvidos e logo enviados a Luanda, de onde saíram embarcados na nau Nossa Senhora do Alecrim para Lisboa, conduzidos por Antônio de Castro de Souza.7 O conde da Ericeira, embora dê menos detalhes

\footnotetext{
3 Relação do felice successo, op. cit., p. 150. Há outra rápida menção a prisioneiros em uma escaramuça anterior nesse mesmo texto, p. 149. Não tenho informações sobre a lei de isenção do cativeiro mencionada pelo governador de Angola. Talvez haja aqui uma referência a polêmicas sobre a liberdade de súditos do Ndongo havidas entre 1653 e 1661, envolvendo Ngola Ari, Antônio Teixeira de Mendonça e seus herdeiros. A esse respeito vide CURTO, José C. A restituição de 10.000 súditos Ndongo "roubados" na Angola de meados do século XVII: uma análise preliminar. In: HENRIQUES, Isabel Castro (ed.). Escravatura e transformações culturais. África - Brasil - Caraíbas. Lisboa: Editora Vulgata, 2002, p. 185-187.

4 CADORNEGA, A. O. História geral das guerras angolanas, tomo II, op. cit., p. 300 e 323.

5 O valor foi cobrado do provedor da Fazenda de Angola em cartas régias de 26 de julho de 1673, 26 de novembro de 1674 e 8 de fevereiro de 1676. Arquivo Histórico Ultramarino (doravante AHU). Registro de cartas, regimentos e ordens para Angola, 1673-1725, cod. 545, fls. 4, 10 e 15v. Luiz Felipe de Alencastro, baseado em José Matias Delgado (in: CADORNEGA, A. O. História geral das guerras, tomo II, nota 80, p. 546-547) avalia que "os ambumdos capturados na batalha e vendidos em seguida ao Brasil renderam um total de 3:551\$000 réis ao Tesouro Régio e aos traficantes angolistas". ALENCASTRO, Luiz Felipe de. O trato dos viventes. São Paulo: Companhia das Letras, 2000, p. 108.

6 CADORNEGA, A. O. História geral das guerras angolanas, tomo II, op. cit., p. 326. A Relação do felice successo, op. cit., p. 151 indica que a morte de dom João Ari foi cometida pelos soldados portugueses, a seu pedido.

7 Alferes e depois capitão de infantaria e cavalaria, Antônio de Castro de Souza havia lutado nas guerras da Restauração em Portugal e chegara a Angola em 1662, onde foi primeiro escrivão de Matrícula e Fazenda Real por três anos e depois ouvidor e auditor geral e juiz governador do
} 
rev. hist. (São Paulo), n. 175, p. 205-225, jul.dez., 2016 http://dx.doi.org/10.11606/issn.2316-9141.rh.2016.121827
Silvia Hunold Lara

Depois da Batalha de Pungo Andongo (1671): 0 destino atlântico dos príncipes do Ndongo

sobre os eventos ocorridos no sertão centro-africano, completa sua descrição informando que a notícia da vitória sobre o Ndongo chegou a Lisboa em 20 de agosto de 1672, que dom Diogo foi mandado para a Torre de São Gião (forte de São Julião da Barra, em Lisboa) e dom Felipe para o convento de Alcobaça. ${ }^{8}$

Os relatos posteriores são menos ricos em detalhes ${ }^{9}$ e só se pode saber mais sobre o destino da família real do Ndongo por meio de alguns poucos documentos administrativos. Eles informam que, no dia seguinte à chegada da nau vinda de Luanda, houve uma sessão do Conselho Ultramarino para deliberar sobre o destino dos africanos que haviam chegado a Lisboa e de outros "14 parentes mais chegados do rei do Ndongo" que haviam sido enviados para o Brasil. ${ }^{10}$ Determinou-se que dom Diogo, como indicou Ericeira, devia ser enviado para a fortaleza de São Julião da Barra, com pensão de \$200 réis por dia e recomendação para não ser obrigado a nenhum trabalho, até que se resolvesse de outra forma - mas ele logo morreu de bexigas. ${ }^{11}$ Dom Felipe devia ser remetido para o convento de Alcobaça, para ser ensinado e doutrinado, mas permaneceu em Lisboa até pelo menos maio do ano seguinte, quando finalmente seguiu seu destino. ${ }^{12}$ Recomendava-se que, como "filho de um

contrato do Reino de Angola. Defendeu o governador Tristão da Cunha durante o motim de 1667. Por seus méritos, foi escolhido pelo governador Francisco de Távora para levar a notícia da vitória sobre o Ndongo a Lisboa, acompanhando dom Felipe e dom Diogo. Em 1675, foi nomeado mestre de campo do Reino de Angola. Cf. Consulta do Conselho Ultramarino de 21 de junho de 1675. AHU, Angola, cx. 11, doc. 47. Cadornega o identifica ainda como "o capitão que havia sido de Cavalos" e ainda "cavaleiro professo do Hábito [da Ordem] de Cristo", mas José Matias Delgado o chama de ouvidor geral. CADORNEGA, A. O. História geral das guerras angolanas, tomo II, op. cit., p. 328 e nota 81 de J. M. Delgado na p. 547.

8 Relação do felice successo, op. cit., p. 152.

9 Elias Alexandre da Silva Correa em sua História de Angola e no Catálogo dos governadores traz descrições abreviadas da campanha contra o Ndongo. O primeiro menciona a fuga do rei, mas observa que dois de seus irmãos "além de muitos outros" ficam prisioneiros. O segundo data a batalha final a 18 de agosto de 1671 e indica que o rei se suicidou ao jogar-se dos rochedos, ficando prisioneiros dois de seus irmãos. Cf. CORREA, Elias Alexandre da Silva. Historia de Angola, vol. I. Lisboa: [Editorial Ática] 1937 [1787-99], p. 293; e Catalogo dos governadores do Reino de Angola [1784]. Colleç̧ão de noticias para a historia e geografia das nações ultramarinas..., tomo III. Lisboa: Typografia da Academia Real das Sciencias, 1825, parte I, p. 391-392. Sobre a relação entre esses dois textos ver MILLER, Joseph C. $\mathcal{E}$ THORNTON, John K. The chronicle as source, history, and hagiography: the Catálogo dos governadores de Angola. Paideuma, 33, 1987, p. 359-389.

${ }^{10}$ Consulta do Conselho Ultramarino de 21 de agosto de 1672. AHU, Angola, cx. 10, doc. 71 (MMA, vol. XIII, doc. 73, p. 180-181).

${ }^{11}$ Batismo do príncipe de Dongo. MMA, vol. XIII, doc. 125, p. 297-298 e Consulta do Conselho Ultramarino de 21 de junho de 1675. AHU, Angola, cx. 11, doc. 47.

12 Antes de ser enviado a Alcobaça, dom Felipe deve ter permanecido em casa de Antônio de Castro de Souza, onde ficara juntamente com dom Diogo, ao chegar em Lisboa. Consulta do Conselho 
rev. hist. (São Paulo), n. 175, p. 205-225, jul.dez., 2016 http://dx.doi.org/10.11606/issn.2316-9141.rh.2016.121827
Silvia Hunold Lara

Depois da Batalha de Pungo Andongo (1671): 0 destino atlântico dos príncipes do Ndongo

rei", fosse bem educado nas matérias da fé e das "boas artes". ${ }^{13}$ Em Alcobaça, era chamado por "excelência" e tinha o primeiro lugar no coro, apesar de ser uma criança de cerca de 10 anos. Foi batizado na capela mor do convento em maio de $1674,{ }^{14}$ sendo sustentado e vestido a expensas do Tesouro Régio. ${ }^{15}$

Mais interessante é a história dos 14 "parentes mais chegados do dito rei" que, por ordem do governador de Angola, foram embarcados para o Brasil e não chegaram sequer a ser mencionados nos relatos de Cadornega e do conde da Ericeira, muito menos na História de Angola de Elias Alexandre da Silva Correa e no Catálogo dos governadores. ${ }^{16}$ Francisco de Távora havia recomendado que eles não saíssem do Brasil "pela perturbação que poderiam causar" se voltassem a Angola. Ao invés disso, na reunião de 21 de agosto de 1672, os conselheiros do Ultramarino acharam melhor serem levados para Lisboa, para "se evitar o dano que se pode seguir de buscarem meio de fugirem para os mocambos, de onde, conhecidos dos negros deles, nos sejam mais prejudiciais". ${ }^{17}$ A sugestão obteve a concordância do príncipe regente em setembro de 1672, que então escreveu ao governador do Estado do Brasil, recomendando que, caso os "negros" não estivessem em Salvador, fossem embarcados do lugar onde se achassem. ${ }^{18}$

A observação revela ao mesmo tempo pressa e problemas. De fato, nem todos haviam desembarcado em Salvador: dom Inácio, dom Lourenço, dom Simão, dom João e dom Gaspar, "netos legítimos de El Rei dom Felipe", acompanhados por "Cristóvão, fidalgo daquela corte", haviam ficado no Rio de

\footnotetext{
Ultramarino de 21 de junho de 1675. AHU, Angola, cx. 11, doc. 47. Segundo o documento Batismo do príncipe de Dongo (MMA, vol. XIII, doc. 125, p. 297-298), o príncipe chegou a Alcobaça em 29 de maio de 1673. Ver também Decreto Régio de 9 de maio de 1673 e Consulta do Conselho Ultramarino de 15 de maio de 1673. AHU, Angola, cx. 10, doc. 107 (MMA, vol. XIII, doc. 102, p. 227 e 226).

${ }^{13}$ Carta do regente dom Pedro ao superior de Alcobaça de 24 de novembro de 1673. MMA, vol. XIII, doc. 109, p. 239. Talvez houvesse alguma intenção de um dia levar dom Felipe de volta ao Reino de Angola, restaurando o Ndongo inteiramente sob domínio português, mas a hipótese não pode ser confirmada pela documentação.

${ }^{14}$ Batismo do príncipe de Dongo, MMA, vol. XIII, doc. 125, p. 297.

${ }^{15}$ Relação do felice successo, op. cit., p. 12; Consulta do Conselho Ultramarino de 21 de agosto de 1672. AHU, Angola, cx. 10, doc. 71 (MMA, vol. XIII, doc. 73, p. 180-181); e Consulta do Conselho Ultramarino de 15 de maio de 1673. AHU, Angola, cx. 10, doc. 107 (MMA, vol. XIII, doc. 102, p. 226).

${ }^{16}$ Mereceram a atenção, entretanto, de José Matias Delgado e de Ralph Delgado. Cf. J. M. Delgado, notas 81 e 82. CADORNEGA, A. O. História geral das guerras angolanas, tomo II, op. cit., p. 547-548 e DELGADO, Ralph. História de Angola. $2^{\mathrm{a}}$ edição. [Lisboa]: Banco de Angola, [1973], vol. III, p. 400-402.

17 Consulta do Conselho Ultramarino de 21 de agosto de 1672 e Despacho régio de 2 de setembro de 1672. AHU, Angola, cx. 10, doc. 71 (MMA, vol. XIII, doc. 73, p. 180-181).

${ }^{18}$ Carta régia para o governador do Estado do Brasil de 6 de setembro de 1672. AHU_ACL_CU_ CARTAS RÉGIAS, Cod. 276, fl. 69v (Documentos históricos, 67, 1945, p. 213-214).
} 
rev. hist. (São Paulo), n. 175, p. 205-225, jul.dez., 2016 http://dx.doi.org/10.11606/issn.2316-9141.rh.2016.121827
Silvia Hunold Lara

Depois da Batalha de Pungo Andongo (1671): 0 destino atlântico dos príncipes do Ndongo

Janeiro. Tudo indica que, dos que chegaram a Salvador, apenas quatro foram enviados a Lisboa imediatamente. Quase um ano depois, em agosto de 1673, os seis do Rio de Janeiro juntaram-se a outros quatro remanescentes do grupo que desembarcou na Bahia (dom Gaspar e dom Domingos, "filhos legítimos da segunda mulher de El Rei dom Felipe", dom Inácio, seu sobrinho, e Domingos, escravo), e seguiram para Lisboa, na nau São Veríssimo, capitânia da frota daquele ano. ${ }^{19}$ Dona Joana, neta do rei dom Felipe, permaneceu na Bahia, "por estar enferma". ${ }^{20}$ Assim como havia acontecido com dom Diogo e dom Felipe, os recém-chegados ficaram hospedados em casas particulares - desta vez nas dos conselheiros do Ultramarino - até que seus respectivos destinos fossem decididos pelo regente. ${ }^{21}$

A relação dos que foram enviados pela frota do Brasil para o Reino, elaborada por Bernardo Vieira Ravasco, secretário do Estado e Guerra do Brasil, e um apenso anexo à carta de Antônio de Castro de Souza dirigida ao secretário do Conselho Ultramarino, Manuel Barreto de Sampaio, indicando a "Repartição [dos "príncipes pretos] pelos conventos de Lisboa e Reino" permitem saber algo sobre os últimos membros da família real do Ndongo. ${ }^{22}$

\footnotetext{
${ }^{19}$ Carta do governador-geral do Brasil ao príncipe regente de 7 de agosto de 1673 e Relação dos príncipes que vinham de Angola por mandado do governador Francisco de Távora... (por Bernardo Vieira Ravasco) AHU_ACL_CU_005-02, cx. 22, doc. 2545 - 2546. Um recibo, datado de 24 de maio de 1673 e assinado por Francisco Gonçalves Ferraz (AHU_ACL_CU_005, cx. 2, doc. 181), registra o recebimento de "seis escravos, digo negros príncipes para entregar ao secretário do Conselho Ultramarino". Todos esses documentos são mencionados na Carta de Antônio de Castro de Souza ao secretário do Conselho Ultramarino, Manuel Barreto de Sampaio, de 24 de agosto de 1673. AHU, Angola, cx. 10, doc. 128 (MMA, vol. XIII, doc. 107, p. 234-236). O lapso cometido por Gonçalves Ferraz é comentado rapidamente por Stuart B. Schwartz em Introdução. In: SCHWARTZ, Stuart B. E PÉCORA, Alcir (ed.). As excelências do governador. São Paulo: Companhia das Letras, 2002, p. 32.

${ }^{20}$ Relação dos príncipes que vinham de Angola por mandado do governador Francisco de Távora... AHU_ACL_CU_005-02, cx. 22, doc. 2545 - 2546.

${ }^{21}$ Consulta do Conselho Ultramarino de 25 de agosto de 1673. AHU_ACL_CU_CONSULTAS DA BAHIA, cod. 252, fl 10. A minuta de Consulta do Conselho Ultramarino de 8 de novembro de 1673 confirma a chegada dos dez "negros, príncipes do Ndongo", em Lisboa. AHU_ACL_CU_00502, cx. 22, doc. 2565. A Memória dos príncipes pretos que vieram de Angola, anexa à carta de Antônio de Castro de Souza ao secretário do Conselho Ultramarino, Manuel Barreto de Sampaio, de 24 de agosto de 1673. AHU, Angola, cx. 10, doc. 128 (MMA, vol. XIII, doc. 107, p. 236) indica que um deles ficou hospedado na casa do marquês das Minas, presidente do Conselho Ultramarino.

${ }^{22}$ Relação dos príncipes que vinham de Angola por mandado do governador Francisco de Távora... AHU_ACL_CU_005-02, cx. 22, doc. 2545 - 2546; e Repartição [dos príncipes pretos] pelos conventos de Lisboa e Reino. Anexo à carta de Antônio de Castro de Souza ao secretário do Conselho Ultramarino, Manuel Barreto de Sampaio, de 24 de agosto de 1673. AHU, Angola, cx. 10, doc. 128 (MMA, vol. XIII, doc. 107, p. 234-236). O fato de terem sido escritas em datas
} 
rev. hist. (São Paulo), n. 175, p. 205-225, jul.dez., 2016 http://dx.doi.org/10.11606/issn.2316-9141.rh.2016.121827
Silvia Hunold Lara

Depois da Batalha de Pungo Andongo (1671): 0 destino atlântico dos príncipes do Ndongo

Nem sempre os nomes coincidem e às vezes as indicações não são precisas, mas pelo cruzamento das informações chega-se à conclusão de que, excetuando-se o "fidalgo" Cristóvão e um escravo, ${ }^{23} 16$ descendentes do $11^{\circ}$ rei do Ndongo, dom Felipe I Ngola Ari, foram enviados a Lisboa.

As relações de parentesco entre eles podem ser sistematizadas conforme o quadro abaixo:

\section{Membros da família real do Ndongo enviados a Lisboa}

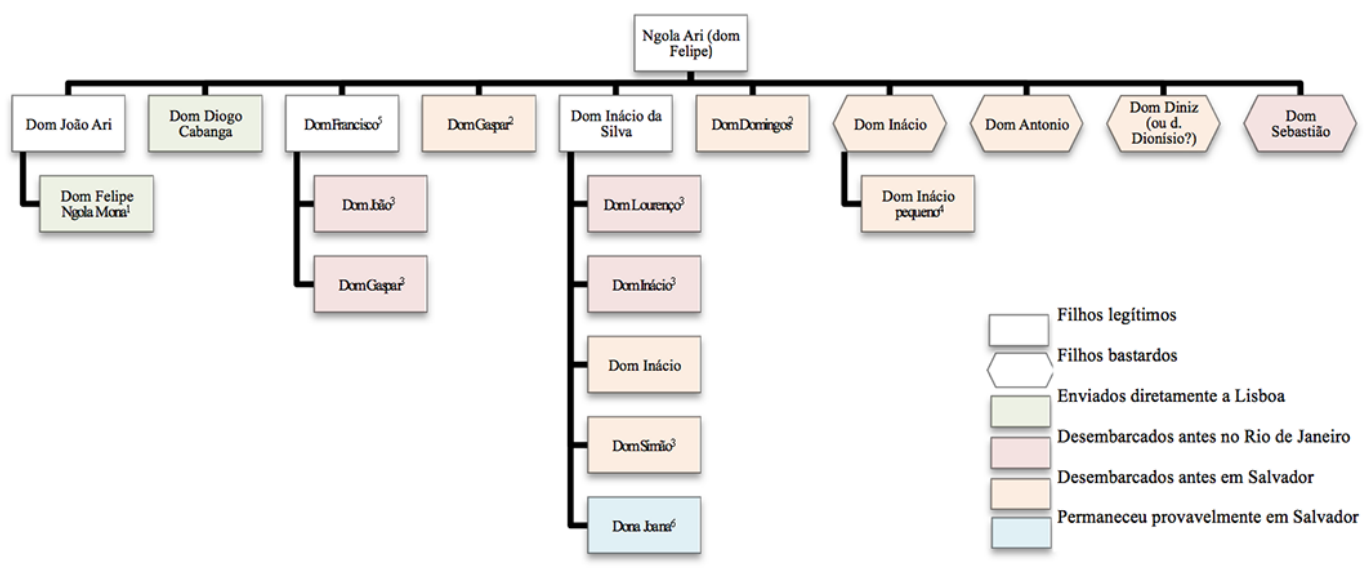

Observações:

1 Filho do rei dom João Ari e da rainha Cabaça (dona Joana), ambos mortos na batalha de Pungo Andongo. (Batismo do príncipe do Ndongo, MMA, vol. XIII, doc. 125, p. 297).

2 Filhos legítimos da segunda mulher de dom Felipe (Relação dos príncipes que vinham de Angola por mandado do governador Francisco de Távora... AHU_ACL_CU_005-02, cx. 22, doc. 2546).

3 Netos legítimos de dom Felipe (Relação dos príncipes que vinham de Angola por mandado do governador Francisco de Távora... AHU_ACL_CU_005-02, cx. 22, doc. 2546).

4 A carta de Antônio de Castro de Souza menciona um "Inácio pequeno, filho da irmã", sem entretanto indicar se irmã de dom Feilipe ou de dom Diogo. Com a existência de vários "Inácios", suponho que o atributo "pequeno" possa ter sido dado para diferenciá-lo do pai - hipótese sustentada por outra observação existente nesse mesmo documento (Carta de Antônio de Castro de Souza de 24 de agosto de 1673. AHU, Angola, cx. 10, doc. 128).

muito próximas (uma na Bahia, provavelmente em 7 de agosto de 1673, e outra em Lisboa, em 24 de agosto de 1673) indica que mesmo antes da chegada do grupo em Portugal já se tinha conhecimento detalhado de suas identidades.

${ }^{23}$ A Relação de Bernardo Vieira Ravasco indica que "Domingos, escravo" desembarcou na Bahia. A carta de Antônio de Castro de Souza de 24 de agosto de 1673 não faz referência a ele, mas menciona "o negro Francisco (...) que diz a relação ser ... escravo [de dom Inácio pequeno]". 
rev. hist. (São Paulo), n. 175, p. 205-225, jul.dez., 2016 http://dx.doi.org/10.11606/issn.2316-9141.rh.2016.121827
Silvia Hunold Lara

Depois da Batalha de Pungo Andongo (1671): 0 destino atlântico dos príncipes do Ndongo

5 Faleceu no "tempo dos holandeses" (Carta de Antônio de Castro de Souza de 24 de agosto de 1673. AHU, Angola, cx. 10, doc. 128).

" Dona Joana é identificada como "irmã do dito dom Inácio" na relação escrita no Brasil, mas há duas pessoas com esse nome nessa relação, ambos netos de dom Felipe - um que ficou no Rio de Janeiro e outro em Salvador (Relação dos príncipes que vinham de Angola por mandado do governador Francisco de Távora... AHU_ACL_CU_005-02, cx. 22, doc. 2546). Na Consulta do Conselho Ultramarino de 24 de agosto de 1673 ela aparece descrita como "moça formosa", o que pode indicar ser ainda jovem nessa ocasião. (AHU, Angola, cx. 10, doc. 128).

Como se vê, trata-se de uma família extensa, composta por descendentes de primeira e segunda geração de dom Felipe, que havia morrido em 1664. Ele havia sido o último dos reis do Ndongo a permanecer fiel aos portugueses e talvez por isso a descrição de todas as relações de parentesco o tome por referência. Designados pelo título de "dom" ou como "príncipes negros", e apenas por seus nomes católicos, foram tratados sempre com deferência, explicitando-se o pertencimento à realeza do Ndongo.

Francisco de Távora havia se preocupado sobretudo com o contexto político naquela região da África. O Congo, desde a batalha de Mbuila em 1665 , parecia não mais oferecer grandes perigos, mas as tropas comandadas por João Soares de Almeida contra o conde do Sonho haviam sido derrotadas em 1670, suspendendo as possibilidades de um domínio português sobre aquela região. ${ }^{24}$ Havia ainda problemas com os reinos de Matamba e Kasanje. Em Matamba, a rivalidade entre os que apoiavam Nzinga Amona e Ngola Kanini, mortos entre 1667 e 1670, se desdobrava em tensões que continuavam a dificultar as relações com o governo de Angola, com os missionários e com os comerciantes portugueses. O jaga de Kasanje vinha se tornando cada vez mais poderoso e era preciso ter mão forte para negociar com ele. ${ }^{25}$

O Libolo havia criado dificuldades para entregar dom João Ari, que acabou decapitado. Mas o governante de Matamba enviou dom Diogo vivo aos portugueses, provavelmente na tentativa de conquistar apoio contra seus rivais, partidários de Nzinga Amona. O governador de Angola também evi-

\footnotetext{
${ }^{24}$ Cf. THORNTON, John K. Firearms, diplomacy and conquest in Angola: cooperation and alliance in West Central Africa, 1491- 1671. In: LEE, Wayne E. (ed.). Empires and indigenes: intercultural alliance, imperial expansion, and warfare in the early modern world. Nova York: NYU Press, 2011, p. 186; e VANSINA, Jan. The Kongo Kingdom and its neighbors. In: OGOT, Bethwell Allan (ed.), General history of Africa. Africa from the sixteenth to the eighteenth century, vol. V. Oxford: Heinemann/Unesco, 1992, p. 564-566.

${ }^{25}$ Uma breve análise dessa conjuntura é oferecida por BIRMINGHAM, David. Trade and conflict in Angola. Oxford: Clarendon Press, 1966, p. 123-128. Ver também DELGADO, R. In: História de Angola, vol. III, op. cit., p. 309-403.
} 
rev. hist. (São Paulo), n. 175, p. 205-225, jul.dez., 2016 http://dx.doi.org/10.11606/issn.2316-9141.rh.2016.121827
Silvia Hunold Lara

Depois da Batalha de Pungo Andongo (1671): 0 destino atlântico dos príncipes do Ndongo

tou executar dom Diogo, uma liderança militar de renome na região que havia enfrentado diversas vezes os exércitos portugueses. Sua morte poderia render benefícios de um lado, mas era preciso ter em conta a situação mais ampla das relações com os poderes centro-africanos, ainda muito instável. ${ }^{26}$

Havia ainda a dificuldade em lidar com os que haviam fugido de Pungo Andongo, na fase final da batalha, abrigando-se nos sobados vizinhos. $\mathrm{O}$ governador de Angola entendeu, por ser "uso e costume", que tudo o que pertencia ao rei do Ndongo e aos sobas seus aliados, derrotados, devia ficar à disposição da Fazenda Real. Havia, assim, mais gente a ser aprisionada. O governador chegou a pedir a devolução dos fugitivos, mas, diante da dificuldade em distinguir os que eram "inteiramente cativos do dito rei", consultou Lisboa. Houve debates no Conselho Ultramarino, que considerava ser esta "matéria de cativeiro (...) de grande consideração". Apesar de concordarem com a justiça da guerra e que "todos os escravos" do derrotado rei do Ndongo deviam pertencer à Fazenda Real, sugeriram que o príncipe regente decidisse dar um "perdão geral", permitindo que os fugitivos pudessem permanecer "em poder dos reis e sobas circunvizinhos". ${ }^{27}$ Como informa Cadornega, muitos eram murinda, "forros de sua nascença", e não kijikos, escravos $^{28}$ e era preciso respeitar essa diferença, para satisfazer a "consciência" dos governantes portugueses e evitar "inconvenientes" políticos para o frágil equilíbrio de forças que sustentava o domínio português na região. ${ }^{29}$

O presídio estabelecido em Pungo Andongo após a vitória foi guarnecido com 100 soldados, mas a submissão de vários sobas ainda dependia dos desdobramentos políticos do trunfo militar obtido. O "perdão geral" contribuía para restabelecer a paz com os sobas tornados amigos pela força das ar-

\footnotetext{
${ }^{26}$ THORNTON, J. K. Firearms, diplomacy and conquest in Angola, op. cit., p. 187.

27 A Consulta do Conselho Ultramarino de 30 de agosto de 1672 resume as várias posições dos conselheiros acerca do melhor procedimento a ser tomado. AHU_ACL_CU_CONSULTAS MISTAS, cod. 17, fl. 58-58v. O voto em separado de Salvador Correa de Sá está em AHU, Angola, cx. 10, doc. 71, anexo 1. A Carta régia para o governador de Angola de 28 de setembro de 1672 indica que a decisão final foi pelo perdão, medida mais imediata que também ajudava a repovoar o Reino do Ndongo. AHU_ACL_CU_CARTAS RÉGIAS, cod. 276, fl. 72 (MMA, vol. XIII, doc. 76, p. 185). Cf. também J. M. Delgado In: CADORNEGA, A. O. História geral das guerras, nota 80, tomo II, p. 547.

${ }^{28}$ CADORNEGA, A. O. História geral das guerras angolanas, tomo II, op. cit., p. 329.

${ }^{29}$ Carta régia para o governador de Angola de 28 de setembro de 1672. AHU_ACL_CU_CARTAS RÉGIAS, cod. 276, fl. 72 (MMA, vol. XIII, doc. 76, p. 185).
} 
rev. hist. (São Paulo), n. 175, p. 205-225, jul.dez., 2016 http://dx.doi.org/10.11606/issn.2316-9141.rh.2016.121827
Silvia Hunold Lara

Depois da Batalha de Pungo Andongo (1671): 0 destino atlântico dos príncipes do Ndongo

mas. ${ }^{30} \mathrm{O}$ contexto local recomendava ser melhor que as lideranças militares e políticas do Ndongo fossem desterradas para longe.

Chegando em 1673 a Lisboa, há indicações de que os membros da família real do Ndongo tenham sido distribuídos por conventos ricos fora da Corte: no da Ordem de Cristo, em Tomar (dom Diniz); convento de Santa Cruz em Coimbra (dom Sebastião); Colégio da Companhia de Jesus em Coimbra (dom João); convento de Tibães, dos beneditinos, em Braga (dom Gaspar); convento de Basto em Cabeceiras de Basto (dom Simão); convento de Vilar de Frades em Barcelos (dom Lourenço); convento de Moreira, dos cônegos de Santo Agostinho, próximo ao Porto (dom Inácio); e o convento de Salzedas, dos monges Bernardos, em Tarouca (dom Inácio e dom Cristóvão). Alguns ficaram em Lisboa: no convento de Nossa Senhora da Graça (dom Gaspar), São Vicente (dom Inácio bastardo e dom Inácio pequeno), Santo Elói (dom Domingos) e no Colégio dos Jesuítas (dom Antônio). ${ }^{31}$ Os lugares foram sugeridos por Antônio de Castro de Souza, que observou ainda que os mais jovens deviam ser enviados à Casa dos Catecúmenos, de preferência acompanhados por algum religioso da Companhia de Jesus "filho de Angola ou (...) que lhe saiba a língua".32 $\mathrm{O}$ destino da "princesa Joana" ficou dependente de a rainha querer tê-la a seu serviço ou não, mas ela talvez nunca tenha saído de Salvador. ${ }^{33}$

É difícil saber o motivo da escolha dos lugares, pertencentes a várias ordens religiosas e espalhados pelo centro e norte de Portugal. Razões de segurança podem ter pesado, com a separação das pessoas em diferentes

\footnotetext{
30 Tais razões são explicitadas no voto em separado de Salvador Correa de Sá. AHU, Angola, cx. 10, doc. 71, anexo 1 .

31 "Repartição [dos "príncipes pretos] pelos conventos de Lisboa e Reino" Apenso à carta de Antônio de Castro de Souza de 24 de agosto de 1673. AHU, Angola, cx. 10, doc. 128 (MMA, vol. XIII, doc. 107, p. 235-236). Ver também Consulta de 9 de novembro de 1673 (AHU_ACL_CU_CONSULTAS MISTAS, cod. 17, fl. 129v-130), que indica que o tema também foi objeto de discussão no Conselho de Estado. Ralph Delgado nega que essa distribuição tenha se realizado, mas não oferece fontes para tal. DELGADO, R. In: História de Angola, vol. III, op. cit., p. 401.

32 Antônio de Castro de Souza discrimina o vestuário específico para alguns deles e insiste na necessidade de que todos sejam instruídos na fé católica. Ainda segundo ele, os jovens, se tivessem capacidade, poderiam depois seguir para Évora ou Coimbra; os adultos para a Índia. Carta de Antônio de Castro de Souza ao secretário do Conselho Ultramarino, Manuel Barreto de Sampaio, de 24 de agosto de 1673. AHU, Angola, cx. 10, doc. 128 (MMA, vol. XIII, doc. 107, p. 234-236).

33 Idem. Caso não ficasse a serviço da rainha, a sugestão de Antônio e Castro de Souza era de enviar dona Joana "a Carnide, à senhora dona Maria". Trata-se talvez do mosteiro de Nossa Senhora da Luz, situado na freguesia de Carnide, em Lisboa, construído no século XVI por iniciativa da infanta d. Maria.
} 
rev. hist. (São Paulo), n. 175, p. 205-225, jul.dez., 2016 http://dx.doi.org/10.11606/issn.2316-9141.rh.2016.121827
Silvia Hunold Lara

Depois da Batalha de Pungo Andongo (1671): 0 destino atlântico dos príncipes do Ndongo

conventos ou colégios. Pode-se ter seguido certa tradição, já que pelo menos um deles, o convento de Santo Elói, em Lisboa, havia abrigado jovens vindos do Congo no século XVI. ${ }^{34}$ Talvez o principal motivo tenha sido o de pertencerem a ordens religiosas suficientemente ricas para poderem arcar com os custos de manutenção dos hóspedes, aos quais se recomendava ainda que participassem dos serviços da casa, como faziam os religiosos.

A preocupação das autoridades coloniais em deslocar todos os membros da família real do Ndongo para Lisboa tem também relação direta com o contexto das relações entre Angola e o Brasil. Na segunda metade do século XVII, as capitanias de Bahia e Pernambuco eram as principais áreas produtoras de açúcar da América portuguesa - o maior produtor e exportador mundial de açúcar até por volta de 1680, quando passou a enfrentar a concorrência da produção caribenha. Instalados em zonas de boa terra e com acesso a boas rotas fluviais para o transporte do açúcar, centenas de engenhos eram responsáveis por uma produção que podia chegar a mais de um milhão de arrobas por ano. ${ }^{35}$ Tudo movido pela força de trabalho de milhares de africanos escravizados.

Desde o final do século XVI, a maior parte do tráfico negreiro que se dirigia para as costas do Brasil (e para as Américas) partia dos portos exportadores da África central, primeiro Mpinda e depois Luanda. Ao longo do século XVII, os escravos exportados a partir de Luanda representavam cerca de 50 a $60 \%$ de todo o tráfico negreiro realizado pelos europeus. ${ }^{36}$ Conforme o ritmo das guerras na África central, saíam dessa região entre 9 mil e 12 mil escravos por ano, chegando em ocasiões excepcionais até a 15 mil por ano. ${ }^{37}$ Desses, seguiam para o Brasil a cada ano cerca de 8 a 10 mil. A literatura sobre o assunto é extensa e muitas revisões têm sido feitas desde os trabalhos pioneiros de Maurício Goulart e Philip Curtin, ${ }^{38}$ calculando-se entre 200 e

\footnotetext{
${ }^{34}$ Cf. SAUNDERS, A. C. de C. M. A social history of black slaves and freedmen in Portugal, 1441-1555. Cambridge: Cambridge University Press, 1982, p. 156-158.

35 Para um panorama geral da produção açucareira no Brasil desse período vide SCHWARTZ, Stuart B. Colonial Brazil, c. 1580-c. 1750: plantations and peripheries. In: BETHELL, Leslie (ed.). The Cambridge history of Latin America, colonial Latin America. Nova York: Cambridge University Press, 1984, vol. 2, p. 423-453.

${ }^{36}$ HEYWOOD, Linda M. \& THORNTON, John K. Central Africans, Atlantic Creoles, and the foundation of the Americas, 1585-1660. Cambridge: Cambridge University Press, 2007, p. 268.

37 HEYWOOD, L. M. E THORNTON, J. K. Central Africans, Atlantic Creoles, op. cit., p. 160-161; VANSINA, J. The Kongo Kingdom and its neighbors, op. cit., p. 562-563.

${ }^{38}$ GOULART, Mauricio. A escravidão africana no Brasil das origens à extinção do tráfico. $3^{a}$ edição. São Paulo: Alfa-Omega, 1975 [1950]; CURTIN, Philip. The Atlantic slave trade, a census. Madison: The
} 
rev. hist. (São Paulo), n. 175, p. 205-225, jul.dez., 2016 http://dx.doi.org/10.11606/issn.2316-9141.rh.2016.121827
Silvia Hunold Lara

Depois da Batalha de Pungo Andongo (1671): 0 destino atlântico dos príncipes do Ndongo

360 mil escravos chegados no Brasil no século XVII, a grande maioria deles para Bahia e Pernambuco. ${ }^{39}$ "Sem negros não há Pernambuco e sem Angola não há negros", disse uma vez o padre Vieira. ${ }^{40}$ A famosa frase sintetiza a importância das relações escravistas que uniam a África central e, sobretudo, a região açucareira do nordeste do Estado do Brasil.

Em torno do tráfico de escravos articularam-se muitos interesses que fortaleceram os vínculos administrativos, políticos, militares, econômicos, comerciais e até culturais e religiosos entre as áreas de ocupação portuguesa nos dois lados do Atlântico. Muitos governadores, juízes e provedores mandados para Angola haviam ocupado cargos no Brasil e vice versa. ${ }^{41}$ Em muitos anos, aportavam em Luanda mais navios do Brasil do que de Portugal. O Brasil enviava soldados, suprimentos e cavalos para o Reino de Angola e, depois de 1676, o bispo de Angola e Congo tinha que responder ao arcebispado da Bahia. ${ }^{42}$

Os conselheiros do Ultramarino tinham razão ao temer que os príncipes do Ndongo pudessem mais facilmente voltar para Angola se permanecessem no Brasil. Concordando com Távora, recomendaram explicitamente que dom Felipe devia permanecer em conventos de religiosos que não tivessem conexões com colégios situados no Reino de Angola, mandando-o para os cistercienses em Alcobaça. ${ }^{43}$ Acostumados a discutir os assuntos do

University of Wisconsin Press, 1969.

39 Ver ELTIS, David. The volume and structure of the transatlantic slave trade: A reassessment. The William and Mary Quarterly, 58 n. 1, jan. 2001, p. 23-26 e 45; e ALENCASTRO, L. F. Sobre o número de escravos saídos de Angola e entrados no Brasil nos séculos XVI e XVII. In: Idem. $O$ trato dos viventes, op. cit., p. 375-380.

${ }^{40}$ Carta de Antônio Vieira ao marquês de Niza, de 12 de agosto de 1648. AZEVEDO, João Lúcio de (ed.). Antônio Vieira. Cartas. Lisboa: Imprensa Nacional, Casa da Moeda, 1970, vol. 1, p. 234.

${ }^{41}$ Para alguns exemplos, vide GOUVÊA, Maria de Fátima Silva. Conexões imperiais: oficiais régios no Brasil e Angola (c. 1680-1730). In: BICALHO, Maria Fernanda \& FERLINI, Vera Lúcia Amaral (ed.). Modos de governar. Ideias e práticas políticas no Império português (séculos XVI-XIX). São Paulo: Alameda, 2005, p. 179-197; e GOUVÊA, Maria de Fátima Silva E SANTOS, Marilia Nogueira dos. Cultura política na dinâmica das redes imperiais portuguesas, séculos XVII e XVIII. In: ABREU, Martha; SOIHET, Rachel; GONTIJO, Rebeca (ed.). Cultura política e leituras do passado: historiografia e ensino de história. Rio de Janeiro: Civilização Brasileira, 2007, p. 89-110.

${ }^{42}$ Para uma análise das ligações administrativas, militares, políticas e religiosas entre Angola e o Brasil vide PARDO, Anne Wadsworth. A comparative study of the Portuguese colonies of Angola and Brazil and their independence from 1648-1825. Tese de doutorado, Boston University, Boston, 1977; e, especialmente, ALENCASTRO, L. F. O trato dos viventes, op. cit.

43 Consulta do Conselho Ultramarino de 21 de agosto de 1672. AHU, Angola, cx. 10, doc. 71 (MMA, vol. XIII, doc. 73, p. 180). O manuscrito que descreve o batismo do príncipe do Ndongo observa que a escolha deve-se ainda pelo fato de que os primeiros pregadores da fé católica em S. Tomé e Congo pertenceram ao real mosteiro de Alcobaça e que o 20 de agosto, data em que o navio 
rev. hist. (São Paulo), n. 175, p. 205-225, jul.dez., 2016 http://dx.doi.org/10.11606/issn.2316-9141.rh.2016.121827
Silvia Hunold Lara

Depois da Batalha de Pungo Andongo (1671): 0 destino atlântico dos príncipes do Ndongo

governo ultramarino, sabiam das ligações entre os missionários das diversas ordens religiosas e os poderes locais centro-africanos. Seria bom evitar problemas potenciais.

Mas havia mais: havia o perigo político do contato dos membros da família real do Ndongo com os mocambos - nome dado às comunidades de escravos fugitivos no Brasil.

Desde que a presença de escravos africanos aumentara na América portuguesa, haviam se formado comunidades de fugitivos de tamanho e duração variadas. Existiam várias no sertão da Bahia, mas a mais importante era o conjunto de mocambos que havia se instalado na região sul da capitania de Pernambuco desde o início do século XVII. Esses mocambos tinham crescido bastante durante o período do domínio holandês em Pernambuco (1630-1654) e estavam bem organizados e fortificados, espalhados por uma região de cerca de 300 quilômetros, conhecida como Palmares. O maior deles chamava-se Macaco e ficava próximo à vila de Porto Calvo. Depois vinham Subupira, Amaro, Andalaquituche, Aca Inene, Tabocas, Zambi, Dambiabanga e outras unidades menores. ${ }^{44}$ Os relatos militares e as crônicas oficiais da segunda metade do século XVII mencionam haver entre 11 e 20 mil pessoas estabelecidas nos vários mocambos. Os números são obviamente exagera$\operatorname{dos}_{,}{ }^{45}$ mas revelam a importância e o impacto político daquela duradoura e renitente comunidade de fugitivos.

Desde o final dos anos 1660 e especialmente na década de 1670, as autoridades coloniais conheciam os nomes dos governantes desses mocambos, sabiam das relações de parentesco entre eles e chamavam seu líder, Gana Zumba, de "rei dos Palmares". Os governadores e comandantes militares de Pernambuco, assim como os conselheiros do Ultramarino, discutiam as diversas estratégias que podiam ser adotadas para eliminar esse estado linhageiro de matriz centro-africana que havia se formado na região sul de Per-

\footnotetext{
vindo de Angola entrou em Lisboa, é dia de São Bernardo, personagem importante para essa ordem religiosa. Batismo de príncipe de Dongo, MMA, vol. XIII, doc. 125, p. 298, p. 297-298.

${ }^{44}$ Relação anônima, sem data. Arquivo Nacional da Torre do Tombo. Manuscritos da Livraria, n. 1185, Papéis vários, tomo $1^{\circ}$, fls. 149-155v. Publicada com o título Relação das guerras feitas aos Palmares de Pernambuco no tempo do governador dom Pedro de Almeida de 1675 a 1678. Revista do Instituto Histórico e Geográfico Brasileiro, n. 22, 1859, p. 303-329.

${ }^{45}$ Comentando estas cifras, Stuart B. Schwartz considerou que, se a região possuía cerca de 200 engenhos em meados do século XVII, com a média de 100 escravos cada um, o número de habitantes de Palmares igualaria o total de escravos na economia açucareira na região. Vide SCHWARTZ, Stuart B. Rethinking Palmares: slave resistance in colonial Brazil. In: Idem. Slaves, peasants, and rebels. Urbana: University of Illinois Press, 1992, p. 123.
} 
rev. hist. (São Paulo), n. 175, p. 205-225, jul.dez., 2016 http://dx.doi.org/10.11606/issn.2316-9141.rh.2016.121827
Silvia Hunold Lara

Depois da Batalha de Pungo Andongo (1671): 0 destino atlântico dos príncipes do Ndongo

nambuco. A partir de 1671, quando o governador de Pernambuco Francisco de Souza Coutinho enviou uma proposta para destruir de vez os Palmares, o tema apareceu em muitas reuniões do Conselho Ultramarino. ${ }^{46}$

Os membros da família real do Ndongo que chegaram ao Brasil podiam não ser de fato conhecidos pelos habitantes dos Palmares, mas sua importância como membros de uma linhagem da aristocracia centro-africana podia ser reconhecida por eles com facilidade. A constatação, feita por gente acostumada a lidar com as questões da administração colonial, tinha um peso político evidente. O retorno da linhagem real ao Reino de Angola podia por em risco a vitória obtida em Pungo Andongo, mas a permanência no Brasil poderia oferecer outro perigo: o que aconteceria caso a linhagem do Ndongo se juntasse àquela que governava Palmares? A pergunta não é destituída de interesse - e certamente foi feita pelas autoridades coloniais que julgaram melhor mandar aqueles prisioneiros para Portugal.

A estadia dos príncipes em Portugal não foi tranquila. As poucas fontes sobre eles indicam que os que haviam permanecido na Corte fizeram "alguns desmandos" e foram enviados para a fortaleza de Peniche onde permaneceram por muitos anos. ${ }^{47}$ De início, havia remessas regulares para seu sustento, relativamente avultadas, mas elas foram escasseando e, em 1679, o Conselho Ultramarino aventou a possibilidade de devolvê-los para Angola ou para o Brasil. Francisco de Távora, que havia retornado do Reino de Angola há cerca de três anos, chegou a ser consultado e, mudando o encaminhamento que havia tomado logo depois da batalha de Pungo Andongo, acabou por concordar com a decisão do Conselho em 1672, mas de forma mais explícita e contundente. Agora, para ele, nenhuma das alternativas era conveniente, pois

\footnotetext{
${ }^{46}$ Cf. Carta de Fernando de Souza Coutinho de $1^{\circ}$ de junho de 1671 e Consulta do Conselho Ultramarino de 9 de outubro de 1671. Respectivamente AHU_ACL_CU_015, cx. 10, doc. 917 e AHU_ACL_CU_Consultas Mistas, cod. 17. Os debates no Conselho Ultramarino podem ser acompanhados no dossiê que acompanha a carta de Souza Coutinho. Ao que tudo indica, o regente não tomou nenhuma decisão e o assunto continuou pendente, sendo retomado na nomeação do novo governador, dom Pedro de Almeida. Ver Consulta do Conselho Ultramarino de 18 de novembro de 1673. AHU_ACL_CU_Consultas de Pernambuco, cod. 265, fls. 2-2v. Para uma breve análise da história de Palmares na década de 1670, vide LARA, Silvia Hunold. Marronnage et pouvoir colonial. Palmares, Cucaú et les frontières de la liberté au Pernambouc à la fin du XVIIe siècle. Annales, 67, n. 3, maio-jun. 2007, p. 639-662. Ver também THORNTON, John K. Les États de l'Angola et la formation de Palmares (Brésil). Annales, 63, 2008, p. 769-797.

${ }^{47}$ Consulta do Conselho Ultramarino de 28 de novembro de 1675. AHU_ACL_CU_CONSULTAS MISTAS, cod. 17, fl. 187 (MMA, vol. XIII, doc. 159, p. 381-382).
} 
rev. hist. (São Paulo), n. 175, p. 205-225, jul.dez., 2016 http://dx.doi.org/10.11606/issn.2316-9141.rh.2016.121827
Silvia Hunold Lara

Depois da Batalha de Pungo Andongo (1671): 0 destino atlântico dos príncipes do Ndongo

em Angola, com o séquito que tinham, podiam alterar aquele gentio, de modo que nos fosse de grande prejuízo, e no Brasil havia o mesmo, ou por poderem fugir para Angola, ou meterem-se com os negros dos Palmares, com que lhe parecia ser mais ajustado passá-los ao Maranhão, donde não havia embarcações que fossem a Angola e menos negros com que se acumulassem. ${ }^{48}$

Seguindo a sugestão, o Conselho indicou ao rei que os príncipes fossem então remetidos para o Maranhão ou para o Pará, onde seriam engajados como soldados ou poderiam usar "de sua indústria e trabalho" para viverem. ${ }^{49}$ Como se pode verificar, o medo político do renascimento do Reino do Ndongo no interior da África central e da aliança com os Palmares em Pernambuco continuava presente, mesmo depois de tantos anos.

A proposta de envio dos príncipes para as capitanias do norte da América portuguesa parece não ter vingado. Os que foram mandados para a fortaleza de Peniche continuaram ali por mais de uma década. Em 1682 e 1695 , registram-se novos pedidos de mais dinheiro para seu sustento, vestimentas adequadas e cuidado nas doenças. ${ }^{50}$ Em 1697, ao menos o "príncipe preto dom Gaspar de Araújo" ainda permanecia em Peniche. ${ }^{51}$

O périplo dos membros da família real do Ndongo revela dimensões da comunicação entre partes importantes do Império colonial português pouco abordadas pela historiografia. Quero destacar aqui alguns pontos que considero importantes.

Em primeiro lugar, é preciso observar que as conexões atlânticas entre o Brasil e Angola não se limitavam aos carregamentos de escravos e outras mercadorias, nem aos laços entre administradores, padres, missionários e demais agentes coloniais. Elas também podiam envolver a circulação de notícias e até ligações políticas entre os africanos situados nas duas margens

\footnotetext{
${ }^{48}$ Consulta do Conselho Ultramarino de 18 de julho de 1679. AHU_ACL_CU_CONSULTAS MISTAS, cod. 17, fl. 301 (publicado em MMM, vol. XIII, doc. 206, p. 507-508).

${ }^{49}$ Consulta do Conselho Ultramarino de 18 de julho de 1679. AHU_ACL_CU_CONSULTAS MISTAS, cod. 17, fl. 301 (publicado em MMM, vol. XIII, doc. 206, p. 507-508).

${ }^{50}$ Consulta do Conselho Ultramarino de 12 de junho de 1682. AHU, Angola, caixa 12, doc. 77 (publicado em MMM, vol. XIII, doc. 222, p. 532-533). A. Brásio não transcreve o despacho régio de 16 de junho de 1682, que manda continuar com o sustento e o cuidado nas doenças dos "príncipes pretos". Ver também Consultas do Conselho Ultramarino de 9 de julho de 1695. AHU_ACL_CU, Consultas de partes, cod. 50, fl. 316v. Esse documento informa que são três os príncipes pretos que permanecem em Peniche.

${ }^{51}$ Consulta do Conselho Ultramarino de 6 de novembro de 1697. AHU_ACL_CU, Consultas de partes, cod. 51, fl. 120v-121. Esse documento trata do pagamento de um cirurgião que havia cuidado de umas chagas nos pés de dom Gaspar de Araújo.
} 
do Atlântico. Por isso mesmo, o temor das autoridades coloniais era duplo. De um lado, ficando no Brasil, a família real do Ndongo poderia voltar ao Reino de Angola, pondo a perder a vitória conseguida em Pungo Andongo. $\mathrm{Ou}$, por outro lado, poderia "interiorizar-se", entrando em contato com os governantes dos Palmares.

Os esforços militares para derrotar o Reino do Ndongo e por fim às rebeliões dos nativos na África central eram paralelos aos que ocorriam do outro lado do Atlântico para combater os Palmares. As ligações comerciais e políticas entre o Brasil e Angola não aproximavam apenas autoridades coloniais e traficantes que atuavam ou tinham interesses nas duas margens do Atlântico - elas podiam conectar também os africanos. As notícias sobre o que ocorria em Angola e no Brasil poderiam circular de diferentes modos e com significados diversos para uns e outros. Os conselheiros do Ultramarino podem ter discordado dos encaminhamentos inicialmente dados por Francisco de Távora, quando governador de Angola, mas depois todos pareciam ter avaliações convergentes a respeito das várias áreas do Império português. A preocupação em afastar os membros da família real do Brasil e de Angola indica que, para as autoridades coloniais e metropolitanas, a possibilidade de comunicação entre os africanos era forte e perigosa o suficiente para ser evitada a todo o custo.

Um segundo ponto de interesse é o fato de que nem todos os africanos eram escravizados - ou considerados passíveis de escravização. As fontes indicam que a guerra final contra o Ndongo gerou de imediato dois tipos de prisioneiros: os que foram traficados como escravos para o Brasil ou para as Américas, e os que foram deportados como prisioneiros políticos para o Brasil e depois para Portugal. Havia ainda aqueles sobre cuja escravização pairavam dúvidas: prisioneiros "isentos do cativeiro" ou que haviam fugido de Pungo Andongo durante e logo após a guerra, cujo destino fora discutido pelo Conselho Ultramarino. Na ocasião, não se tratou simplesmente de saber se a guerra havia sido justa ou não, mas de respeitar diferenças sociais e políticas entre os centro-africanos e levá-las em conta ao tratar com os poderes locais. Tais aspectos implicavam desdobramentos importantes em relação aos mecanismos que produziam escravos para o tráfico negreiro. Esta questão nem sempre tem sido considerada pela bibliografia que, muitas vezes, tende a discutir os números do tráfico sem contemplar a origem dos escravos ou, quando o faz, privilegia características étnicas e culturais em detrimento de componentes sociais e políticos.

Como se sabe, do ponto de vista português, a legitimidade do domínio colonial dependia do respeito ao princípio da guerra justa e às condições em 
que as pessoas podiam ser ou não escravizadas. Esses princípios também eram importantes para as relações entre portugueses e os poderes políticos centro-africanos: sem eles a política de alianças e cobranças de tributos não podia se concretizar. Os aspectos políticos tinham que ser combinados com o poderio militar a fim de manter o equilíbrio necessário para a continuidade do tráfico de escravos.

Por isso, os príncipes do Ndongo não podiam ser simplesmente incorporados às levas de prisioneiros de guerra que alimentavam o tráfico atlântico. Foram preservados em parte por interesse das lideranças centro-africanas (ao menos do governo de Matamba) e afastados do Reino de Angola por motivos essencialmente políticos por parte dos governadores portugueses. Sua presença em Portugal distingue-se, assim, daquela dos parentes dos reis do Congo que iam a Lisboa estudar ${ }^{52}$ - mesmo quando se aventava a necessidade de serem instruídos nas "boas artes" e até serem depois enviados para Évora ou para Coimbra. ${ }^{53}$

Não deixa de ser irônico que o procedimento tenha sido tão dispendioso. Ainda que o ônus do sustento dos "príncipes negros" em seu périplo atlântico tenha sido arcado por particulares ou que os conventos tenham ajudado a mantê-los durante a longa estadia em Portugal, a Coroa gastou com eles muito mais do que conseguiu arrecadar com os quintos que obteve com a vitória sobre Pungo Andongo.

Por várias vezes, o Conselho Ultramarino reclamou ter poucos recursos para cobrir os gastos com eles, que realmente eram grandes. Em 1673, o envio de d. Felipe para Alcobaça envolveu um custo de pelo menos 32\$000 réis $^{54}$ e os dez que chegaram logo em seguida receberam $100 \$ 000$ réis. $^{55}$ Em 1675, os conselheiros calculavam que os gastos com todos eles somavam, até aquele ano, 1:88\$560 réis; ${ }^{56}$ em 1679 afirmavam gastar com os que estavam em Peniche cerca de 25\$000 réis por ano e mais $100 \$ 000$ réis para

\footnotetext{
${ }^{52}$ Sobre a presença de nobres congueses em Portugal ver, entre outros, SAUNDERS, A. C. de C. M. A social history of black slaves and freedmen in Portugal, 1441-1555, op. cit., p. 156-158; e NORTHRUP, David. Africa's discovery of Europe, 1450-1850. Nova York: Oxford University Press, 2002.

53 Consulta do Conselho Ultramarino de 15 de maio de 1673. AHU, Angola, cx. 10, doc. 107 (MMA, vol. XIII, doc. 102, p. 226).

${ }^{54}$ Consulta do Conselho Ultramarino de 15 de maio de 1673. AHU, Angola, cx. 10, doc. 107 (MMA, vol. XIII, doc. 102, p. 226).

${ }^{55}$ Consulta do Conselho Ultramarino de 25 de agosto de 1673. AHU_ACL_CU_CONSULTAS DA BAHIA, cod. 252, fl 10.

${ }^{56}$ Consulta do Conselho Ultramarino de 28 de novembro de 1675. AHU_ACL_CU_CONSULTAS MISTAS, cod. 17, fl. 187 (MMA, vol. XIII, doc. 159, p. 381).
} 
rev. hist. (São Paulo), n. 175, p. 205-225, jul.dez., 2016 http://dx.doi.org/10.11606/issn.2316-9141.rh.2016.121827
Silvia Hunold Lara

Depois da Batalha de Pungo Andongo (1671): 0 destino atlântico dos príncipes do Ndongo

o vestuário. ${ }^{57}$ Em 1682, quando se aventou a possibilidade de irem para o Maranhão, o Conselho Ultramarino mencionou que eles "padec[iam] muitas necessidades, passando muitos dias sem comer". ${ }^{58}$ Em 1695, conseguiram que sua pensão fosse aumentada de $\$ 80$ para $\$ 100$ réis por dia. ${ }^{59}$

Pode parecer um custo alto, mas é certamente pequeno em vista do trunfo político representado por ter os legítimos herdeiros do Ndongo prisioneiros. Mantidos em Lisboa, mesmo bem longe do Reino de Angola, ajudavam a reavivar a memória da vitória obtida em 1671 e a servir de exemplo para os que quisessem se rebelar contra o domínio português. Contribuíam assim para assegurar a continuidade dos fluxos do comércio atlântico de escravos, que tanto rendia aos traficantes e ao Tesouro Real. À sombra do presídio português instalado em Pungo Andongo logo se desenvolveu uma feira e o raio de ação dos negreiros pode ir mais longe no sertão centro-africano. ${ }^{60} \mathrm{Um}$ resultado por demais positivo, se lembrarmos que cada um dos 8 a 10 mil escravos levados anualmente de Luanda para o Brasil pagava de direitos de saída $4 \$ 000$ réis e, a partir de 1711, $6 \$ 000$ réis se enviados para as Minas Gerais. ${ }^{61}$ É só fazer as contas.

\footnotetext{
${ }^{57}$ Consulta do Conselho Ultramarino de 12 de junho de 1682. AHU, Angola, cx. 12, doc. 77 (MMA, vol. XIII, doc. 222, p. 532-533). Outros documentos (como citado na nota anterior) mencionam custos de 80 réis por dia. Como pondera o Conselho Ultramarino em 1682, é bem mais do que ganhava um soldado, que recebia meio tostão (ou 40 réis).

${ }^{58}$ Consulta do Conselho Ultramarino de 12 de junho de 1682. AHU, Angola, cx. 12, doc. 77 (MMA, vol. XIII, doc. 222, p. 532-533). Vários dos documentos citados mencionam que eles também sofriam com doenças.

${ }^{59}$ Consulta do Conselho Ultramarino de 9 de julho de 1695. AHU_ACL_CU, CONSULTAS DE PARTES, cod. 50, fl. 316v.

${ }^{60}$ ALENCASTRO, L. F. $O$ trato dos viventes, op. cit., p. 108.

${ }^{61}$ DIAS, Gastão de Souza. Os portugueses em Angola. Lisboa: Agência Geral do Ultramar, 1959, p. 131; Carta régia para o governador geral do Estado do Brasil de 27 de fevereiro de 1711. AHU_ACL_CU_CARTAS DA BAHIA, cod. 246, fls. 287-287v.
} 


\section{Referências bibliográficas}

ALENCASTRO, Luiz Felipe de. $O$ trato dos viventes. São Paulo: Companhia das Letras, 2000.

BIRMINGHAM, David. Trade and conflict in Angola. Oxford: Clarendon Press, 1966.

CURTIN, Philip. The Atlantic slave trade, a census. Madison: The University of Wisconsin Press, 1969.

CURTO, José C. A restituição de 10.000 súditos Ndongo "roubados" na Angola de meados do século XVII: uma análise preliminar. In: HENRIQUES, Isabel Castro (ed.). Escravatura e transformações culturais. África - Brasil - Caraíbas. Lisboa: Editora Vulgata, 2002, p. 185-208.

DELGADO, Ralph. História de Angola. $2^{\text {a }}$ edição. [Lisboa]: Banco de Angola, [1973], 2 vol.

DIAS, Gastão de Souza. Os portugueses em Angola. Lisboa: Agência Geral do Ultramar, 1959.

ELTIS, David. The volume and structure of the transatlantic slave trade: A reassessment. The William and Mary Quarterly, 58, n. 1, jan. 2001, p. 17-46.

GOULART, Mauricio A escravidão africana no Brasil das origens à extinção do tráfico. $3^{\text {a }}$ edição. São Paulo: Alfa-Omega, 1975 [1950].

GOUVÊA, Maria de Fátima Silva $\mathcal{E}$ SANTOS, Marilia Nogueira dos. Cultura política na dinâmica das redes imperiais portuguesas, séculos XVII e XVIII. In: ABREU, Martha; SOIHET, Rachel; GONTIJO, Rebeca (ed.). Cultura política e leituras do passado: historiografia e ensino de História. Rio de Janeiro: Civilização Brasileira, 2007, p. 89-110.

GOUVÊA, Maria de Fátima Silva. Conexões imperiais: oficiais régios no Brasil e Angola (c. 1680-1730). In: BICALHO, Maria Fernanda \& FERLINI, Vera Lúcia Amaral (ed.). Modos de governar. Ideias e práticas políticas no Império português (séculos XVI-XIX). São Paulo: Alameda, 2005, p. 179-197.

HEYWOOD, Linda M. E THORNTON, John K. Central Africans, Atlantic Creoles, and the foundation of the Americas, 1585-1660. Cambridge: Cambridge University Press, 2007.

LARA, Silvia Hunold. Marronnage et pouvoir colonial. Palmares, Cucaú et les frontières de la liberté au Pernambouc à la fin du XVIIe siècle. Annales, 67 n. 3, maio-jun. 2007, p. 639-662.

MILLER, Joseph C. \& THORNTON, John K. The chronicle as source, history, and hagiography: the Catálogo dos Governadores de Angola. Paideuma, 33, 1987, p. 359-389.

NORTHRUP, David. Africa's discovery of Europe, 1450-1850. Nova York: Oxford University Press, 2002.

PARDO, Anne Wadsworth. A comparative study of the Portuguese colonies of Angola and Brazil and their independence from 1648-1825. Tese de doutorado, Boston University, Boston, 1977.

SAUNDERS, A. C. de C. M. A social history of black slaves and freedmen in Portugal, 14411555. Cambridge: Cambridge University Press, 1982.

SCHWARTZ, Stuart B. E PÉCORA, Alcir (ed.). As excelências do governador. São Paulo: Companhia das Letras, 2002. 
SCHWARTZ, Stuart B. Colonial Brazil, c. 1580-c. 1750: plantations and peripheries. In: BETHELL, Leslie (ed.). The Cambridge history of Latin America, colonial Latin America, vol. 2. Nova York: Cambridge University Press, 1984, p. 423-453.

Rethinking Palmares: slave resistance in colonial Brazil. In: Idem. Slaves, peasants, and rebels. Urbana: University of Illinois Press, 1992, p. 103-136.

THORNTON John K. Firearms, diplomacy and conquest in Angola: cooperation and alliance in West Central Africa, 1491-1671. In: LEE, Wayne E. (ed.). Empires and Indigenes: Intercultural alliance, imperial expansion, and warfare in the early modern world. Nova York: NYU Press, 2011, p. 167-191.

THORNTON, John K. Les États de l'Angola et la formation de Palmares (Brésil). Annales, 63, 2008, p. 769-797.

VANSINA, Jan. The Kongo Kingdom and its neighbors. In: OGOT, Bethwell Allan (ed.). General history of Africa. Africa from the sixteenth to the eighteenth century, vol. V. Oxford: Heinemann/Unesco, 1992, p. 546-587.

Recebido: 13/11/2015 - Aprovado: 11/08/2016 